\title{
RANCANG BANGUN SISTEM MANAJEMEN PENGETAHUAN UNTUK MENDUKUNG PROSES PEMBELAJARAN DI FAKULTAS TEKNIK UNIVERSITAS SAM RATULANGI
}

\author{
Yuliani Y.I Kaawoan ${ }^{1}$, Steven Sentinuwo ${ }^{2}$, Alwin Sambul ${ }^{3}$ \\ Teknik Informatika Universitas Sam Ratulangi. Manado, Jl. Kampus Unsrat Bahu, Manado 95115 \\ 120216049@student.unsrat.ac.id ${ }^{1}$, steven@unsrat.ac.id ${ }^{2}$, asambul@unsrat.ac.id ${ }^{3}$
}

\begin{abstract}
Abstrak - Perguruan tinggi di Fakultas Teknik Universitas Sam Ratulangi berperan penting salah satunya dengan menyediakan sarana yang dapat membantu dalam mendukung proses pembelajaran. Kebutuhan akan pengetahuan dalam era globalisasi semakin tinggi sehingga diperlukan suatu sistem yang dapat mengelola data, informasi dan pengetahuan yang ada. Salah satunya dengan membangun Sistem Manajemen Pengetahuan yang berbasis web, yang mengikutsertakan teknologi di dalam pengelolaan pengetahuan untuk mendukung proses pembelajaran. Sistem Manajemen Pengetahuan yang dihasilkan dapat mengumpulkan, menyimpan, mengelola seperti menghapus dan membagikan pengetahuan yang ada di Fakultas Teknik Universitas Sam Ratulangi. Sistem ini dibangun dengan menggunakan Metode Knowledge Management System Life Cycle dengan model waterfall. Dengan tahapan KMSLC antara lain pendahuluan, pengumpulan data, analisa sistem, perancangan sistem dan implementasi. Dalam perancangannya, sistem manajemen pengetahuan yang dibangun berbasis Web dengan menggunakan bahasa pemrograman HTML dan PHP dengan MySQL sebagai database server.
\end{abstract}

Kata kunci: Sistem Manajemen Pengetahuan, Proses Pembelajaran, KMSLC.

\section{PENDAHULUAN \\ Seiring dengan berjalannya waktu,} perkembangan teknologi berkembang dengan pesat hal ini dapat terjadi karena adanya pemanfaatan dari ilmu-ilmu pengetahuan khususnya dalam pemanfaatan teknologi. Pengetahuan-pengetahuan yang ada dikelola dan digunakan yakni pengetahuan dalam bentuk tacit dan explicit. Yang dimaksud pengetahuan secara tacit yakni pengetahuan yang masih tinggal pada diri seseorang atau individual seperti pengalaman, pemikiran, percakapan dan lain sebagainya. Sedangkan pengetahuan secara explicit yakni pengetahuan yang telah ditulis dan disimpan atau terdokumentasikan dalam suatu media seperti laporan penelitian, buku pembelajaran, skripsi dan lain sebagainya. Untuk dapat memafaatkan pengetahuan yang telah ada dibutuhkan suatu alat bantu yang mampu mengelola setiap pengetahuan baik tacit dan explicit untuk dapat mendukung proses pembelajaran yang dapat memudahkan perolehan pengetahuan dan dimanfaatkan secara maksimal.

Proses pembelajaran merupakan proses belajar dan mengajar dengan bahan pembelajaran yang bertujuan untuk memperkaya pengetahuan, wawasan, mampu menciptakan pengetahuan dan mampu mengelola pengetahuan dan menggunakan pengetahuan yang ada. Di Universitas Sam Ratulangi Manado terlebuh khusus di Fakultas Teknik telah memanfaatkan penggunaan dari Teknologi baik dalam bidang akademik dan administrasi namun dalam proses pembelajaran masih dibutuhkan sebuah sistem teknologi yang mampu mengelola pengetahuan yang ada sehingga dapat mendukung dalam proses pembelajaran untuk memperoleh dan memanfaatkan pengetahuan dengan semaksimal mungkin.

Sistem Manajemen Pengetahuan merupakan sebuah sistem teknologi informasi yang dikembangkan untuk mendukung seluruh proses dari manajemene pengetahuan yakni penciptaan, penyimpanan, pemindahan dan pengaplikasian pengetahuan. Sistem Manajemen Pengetahuan merupakan solusi yang tepat untuk dijadikan alat bantu teknologi dalam mengatur, mengelola seluruh aktivitas manajemen pengetahuan untuk mendukung proses pembelajaran di Fakultas Teknik Universitas Sam Ratulangi sehingga dengan perancangan sistem manajemen yang dibangun akan mampu meningkatan pemanfaatan dan pengelolaan pengetahuan dan menjadi daya saing bagi fakultas.

\section{LANDASAN TEORI \\ A. LITERATURE REVIEW}

Beberapa jurnal penelitian yang dianalisis untuk di review adalah

i. Karya Euis dkk dengan judul Prototipe Knowledge Management System Untuk Menunjang Pembelajaran Ilearning Dengan Model SECI. Penulis menjelaskan 
pengembangan proses pembelajaran berbasis multimedia online di Perguruan Tinggi Raharja. Prototipe yang dihasilkan memiliki tiga modul yaitu modul diskusi online, modul pencarian dan modul pembuatan artikel knowledge[1].

ii. Karya Hoga dengan judul Sistem Informasi Knowledge Management Pada Perguruan Tinggi STMIK Widya Dharma Pontianak penulis membahas mengenai knowledge sharing yang merupakan pendekatan untuk memfasilitasi pencatatan knowledge dan mendorong efektifitas dalam berbagi [11].

iii. Winda dan Ken dengan judul Penerapan Knowledge Management System (KMS) Berbasis Web Studi Kasus Bagian Teknisi dan Jaringn Fakultas Ilmu Komputer Universitas Sriwijaya, dalam penelitian peneliti mendeskripsikan pentingnya pendokumentasian data dan informasi bagi keberlangsungan kegiatan di universitas yaitu di Fakultas Ilmu Komputer Universitas Sriwijaya [12].

iv. Steven dengan judul Perancangan Model Knowledge Management System di Perguruan Tinggi Dengan Pendekatan Balanced Scorecard , Peneliti berhasil menentukan model-model penerapan Knowledge Management System untuk Perguruan Tinggi, dengan integrasi dari konsep Balanced Scorecard yang dapat mengidentifikasikan manfaat-manfaat penerapannya. Tujuan dari penelitian ini adalah Merancang Model Knowledge Management System dengan Pendekatan Balanced Scorecard Di Perguruan Tinggi [13].

v. Malikus dan Retno Rancang Bangun Dcument Management System Universitas "45" Bekasi, penulis menyampaikan DMS dapat mengurangi resiko kehilangan dokumen beserta biaya penyimpanan. Siklus dimulai dari proses digitalisasi dokumen, penerimaan dokumen, pengolahan mencakup duplikasi distribusi, indexing, penyimpanan dan pemeliharaan sampai pada jadwal retensi dan pemusnahan dokumen [14].

Penelitian ini berbeda dari kelima jurnal yang telah di review untuk dijadikan perbandingan, peneliti melakukan penelitian rancang bangun Sistem Manajemen Pengetahuan umtuk mendukung proses pembelajaran di Fakultas Teknik Universitas Sam Ratulangi dengan melakukan pembagian kuesioner dan analisis data dengan pembuatan sistem menggunakan PHP dan MySQL dengan desain web menggunakan alat bantu editor Dreamweaver.

\section{B. KNOWLEDGE}

Knowledge atau pengetahuan adalah hasil dari proses bagaimana kita mengolah data mentah menjadi sebuah informasi yang berguna. Pengetahuan dibagi menjadi dua yaitu :

i. Tacit Knowledge

Menurut Nasseri (1996), tacit knowledge ialah pengetahuan yang berada dalam pikiran manusia, yang bisa diserap orang lain melalui kolaborasi dan sharing, seperti percakapan antar muka, percakapan antar telepon, training, email, dan lain-lain.

ii. Explicit Knowledge

Explicit knowledge adalah pengetahuan yang terekpresikan dalam kata-kata, angka, bagan, atau dalam berbagai bentuk dokumentasi seperti prosedur operasi standar, paper, laporan penelitian, buku, artikel, manuskrip, paten dan software, dan lain-lain (Nasseri, 1996; Munir, 2008).

\section{KNOWLEDGE MANAGEMENT}

Knowledge Management atau manajemen pengetahuan berakar pada banyak sekali disiplin ilmu sehingga definisi dari manajemen pengetahuan sangat bervariasi

Beberapa definisi diantaranya oleh Tanti dan Tiara (2013) bahwa : "knowledge management adalah proses menangkap dan mendayagunakan keahlian dalam bentuk tacit maupun explicit knowledge"

Robby (2010) bahwa : " manajemen pengetahuan merupakan sebuah siklus dari fase yang mejelaskan penangkapan (capture), penciptaan (creation), kodifikasi (codification), penyebarluasan (sharing), pengaksesan (accessing) aplikasi dan penggunaan kembali pengetahuan dalam organisasi”.

Dari kedua uraian di atas bahwa manajemen pengetahuan merupakan penciptaan, pengumpulan, pendokumentasian, pemanfaatan dan penyebaran serta pengaksesan pengetahuan dan informasi untuk membantu organisisasi sehingga mudah dipakai oleh siapa saja sesuai dengan kebutuhannya.

\section{KNOWLEDGE MANAGEMENT SYSTEM}

Knowledge Management System atau Sistem Manajemen Pengetahuan diartikan secara luas sebagai sistem yang mendukung keseluruhan dari siklus manajemen pengetahuan. Knowledge Management System (KMS) adalah suatu sistem TIK (Teknologi Informasi dan Komunikasi) atau sistem dari KM (Knowledge Management) yang mengelola, mengkombinasikan dan mengintegrasikan fungsi dari masing - masing pengetahuan eksplisit dan tasit dari manajemen pengetahuan. Menurut Rahmawati (2014) bahwa KMS di pandang sebagai sistem yang 
diciptakan untuk memfasilitasi manajemen pengetahuan dan menggunakan kembali pengetahuan yang ada tersebut. Dwi (2013) fasilitas yang disediakan sistem manajemen pengetahuan berupa upload atau memposting materi kuliah (pdf, ppt, klip movie, interactive media ), membangun database berupa artikel, penelitian ilmiah, riset yang bersifat publik dan dapat di search via internet sehingga pengguna dapat bahan sesuai keinginan atau kebutuhan dengan hak akses yang ditentukan.

Sehingga dapat dikatakan KMS merupakan sebuah sistem TIK yang berperan sebagai sarana dan alat bantu yang melakukan keseluruhan aktifitas dari manajemen pengetahuan untuk dipakai sesuai dengan kebutuhan

\section{E. PENCIPTAAN DAN PENGEMBANGAN KNOWLEDGE}

Dalam membuat sebuah knowledge management system, dengan memanfaatkan teknologi maka akan terjadi sejumlah konversi atau transformasi pada knowledge atau pengetahuan. Proses transformasi tersebut dengan membagi knowledge tacit dan explicit dengan 4 proses konversi yaitu Socialization, Externalization, Internalization, Combination (SECI).

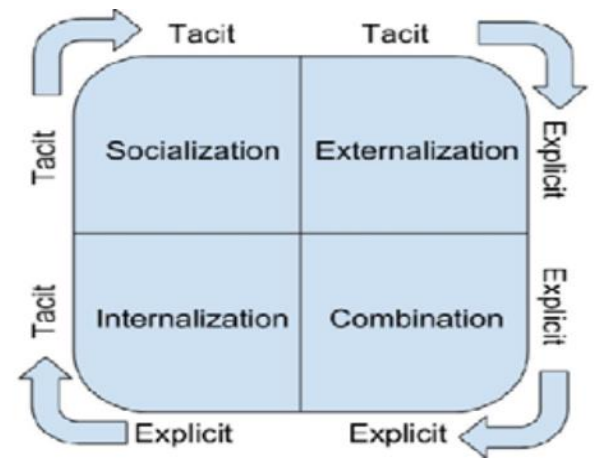

Gambar 1. Proses Konversi Knowledge (SECI)

Dilihat dari Gambar 1. terjadi 4 proses konversi knowledge SECI yaitu :

1. Proses konversi socialization atau tacit ke tacit adalah proses transfer pengetahuan melalui percakapan atau perbincangan dengan berbagi pengalaman, pengamatan, praktek yang merupakan aktifitas dalam mempelajari keterampilan baru.

2. Proses konversi externalization atau tacit ke explicit dimana pengetahuan dituliskan berdasarkan pengalaman maupun analogi ke dalam sebuah tulisan buku, artikel, jurnal, majalah sehingga bermanfaat bagi pembaca atau orang lain yang membutuhkan.

3. Proses konversi combination atau explicit ke explicit merupakan proses konversi dengan memanfaatkan explicit knowledge yang ada dan diimplementasikan menjadi lebih sistematis seperti merangkum buku guna untuk meningkatkan kemampuan dan produktifitas.

4. Proses konversi internalization atau explicit ke tacit yang merupakan explicit knowledge di konversi menjadi tacit knowledge, proses yang biasanya terjadi ketika ecplicit knowledge di paraktekan misalnya, pengajar yang mengajar di dalam kelas dengan referensi dari buku dengan menemukan pengalaman baru dan menerapkan pemahaman baru yang lebih bermanfaat.

Proses transfer atau konversi pengetahuan akan berlangsung berulang-ulang yang telah membentuk sebuah sikus sehingga pengetahuan akan terus berkembang dari waktu ke waktu dan dalam jangka yang panjang akan merberikan manfaat yang besar dalam ilmu pengetahuan. $[1,5,13]$

\section{METODOLOGI PENELITIAN}

Metodoligi dalam penelitian Rancang Bangun Sistem Manajemen Pengetahuan antara lain:

A. Bahan Penelitian

Menggunakan dua jenis data yakni data sekunder (data-data untuk mendukung data primer) berupa referensi buku yang berhubungan dan data primer (data yang diperoleh secara langsung) berupa hasil observasi dengan data yang diperoleh dengan membagikan kuesioner.

B. Tahapan Pengembangan Penelitian Tahapan pengembangan penelitian menjadi acuan kerangka kerja pengembangan penelitian. 


\begin{tabular}{|c|c|c|}
\hline \multicolumn{3}{|c|}{ Berbasis $W e b$} \\
\hline Tahapan & Tindakan & Hasil atau Tools \\
\hline 1. Tahap Pendahuluan & $\begin{array}{c}\text { Mulai } \\
\downarrow \\
\text { Pendahuluan } \\
\text { Persiapan pengumpulan } \\
\text { informasi awal / study literature }\end{array}$ & $\begin{array}{l}\text { Proposal } \\
\text { Penelitian }\end{array}$ \\
\hline $\begin{array}{l}\text { 2. Tahap } \\
\text { Pengumpulan Data }\end{array}$ & \begin{tabular}{|l|}
\multicolumn{2}{|c|}{ Pengumpulan Data } \\
\\
1. Observasi \\
2. Kuesioner \\
3. Studi Pustaka
\end{tabular} & $\begin{array}{l}\text { 1. Data yang } \\
\text { digunakan } \\
\text { pada } \\
\text { penelitian } \\
\text { 2. Landasan } \\
\text { tenri }\end{array}$ \\
\hline $\begin{array}{l}\text { 3. Tahap Analisa } \\
\text { Sistem }\end{array}$ & \begin{tabular}{l}
\multicolumn{1}{|c|}{ Analisa Sistem } \\
\\
1. Analisa proses utama KM \\
2. Analisa sistem
\end{tabular} & \\
\hline $\begin{array}{l}\text { 4. Tahap Perancangan } \\
\text { Sistem }\end{array}$ & $\begin{array}{l}\text { - Perancangan database } \\
\text { - Pemrograman } \\
\text { - Perancangan interface } \\
\text { - Pemrograman }\end{array}$ & \\
\hline $\begin{array}{l}\text { 5. Tahap } \\
\text { Implementasi }\end{array}$ & $\begin{array}{c}\text { Tahap testing dan implementasi } \\
\downarrow \\
\text { Selesai }\end{array}$ & \\
\hline
\end{tabular}

Gambar 2. Metode Pengembangan Penelitian

Tahapan pendahuluan adalah identifikasi seperti mempelajari buku-buku, referensi yang berhubungan. Tahapan pengumpulan data dilakukan dengan membagikan kuesioner di Fakultas Teknik Universitas Sam Ratulangi dan studi pustaka. Tahap Analisa adalah untuk menganalisa data yang dikumpulkan . Dimana sampai saat ini belum ada sistem yang dapat mendukun proses pembelajaran di fakultas teknik universitas sam ratulangi

\section{Tabel 1 Problem Statemant}

\begin{tabular}{|c|c|}
\hline $\begin{array}{l}\text { Rancang Bangun Sistem } \\
\text { Manajemen Pengetahuan }\end{array}$ & Yuliani Y.I Kaawoan \\
\hline Problem & Solution \\
\hline $\begin{array}{l}\text { Tidak adanya wadah } \\
\text { atau sarana dan alat } \\
\text { bantu yang dapat } \\
\text { mengelolah atau } \\
\text { mendukung aktifitas } \\
\text { dari manajemen } \\
\text { pengetahuan dimana } \\
\text { pengetahuan yang } \\
\text { masih berupa tacit } \\
\text { dan explicit. }\end{array}$ & $\begin{array}{lr}\text { Membangun } & \text { sistem } \\
\text { yang } & \text { mampu } \\
\text { melakukan } & \text { dan } \\
\text { mendukung } & \text { semua } \\
\text { proses } & \text { dari } \\
\text { manajemen } \\
\text { pengetahuan sehingga } \\
\text { dapat dimanfaatkan } \\
\text { lebih mudah dan } \\
\text { efisien. }\end{array}$ \\
\hline $\begin{array}{ll}2 . & \text { Sistem Manajemen } \\
& \text { Pengetahuan untuk } \\
\text { mendukung Proses } \\
\text { Pembelajaran } \\
\text { Fakultas Teknik } \\
\text { UNSRAT }\end{array}$ & $\begin{array}{l}\text { Melakukan } \\
\text { identifikasi, analisa } \\
\text { pada permasalahan } \\
\text { dan perancangan } \\
\text { sistem yang sesuai } \\
\text { dengan kebutuhan. }\end{array}$ \\
\hline
\end{tabular}

Tahap perancangan sistem, sistem dirancang sesuai kebutuhan pengguna dan sesuai dengan fungsi manajemen pengetahuan, tahap implementasi dilakukan penerapan metode yang diimplemetasikan dalam basis data dan coding program.

C. Prosedur Perancangan Sistem Dalam pelaksanaan penelitian diperlukan perancangan kerangka kerja antara lain:

1. Proses Bisnis

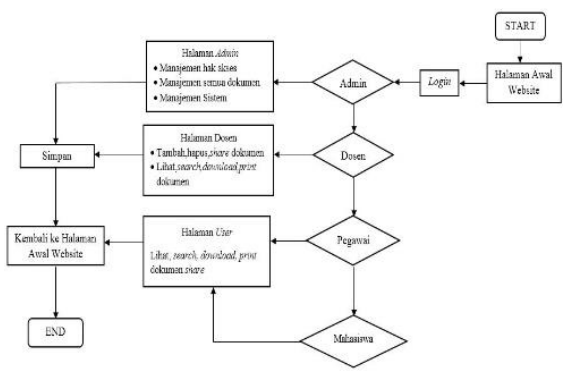

Gambar 3. Proses Bisnis Sistem

Proses bisnis sistem merupakan gambaran pengguna dalam sistem.

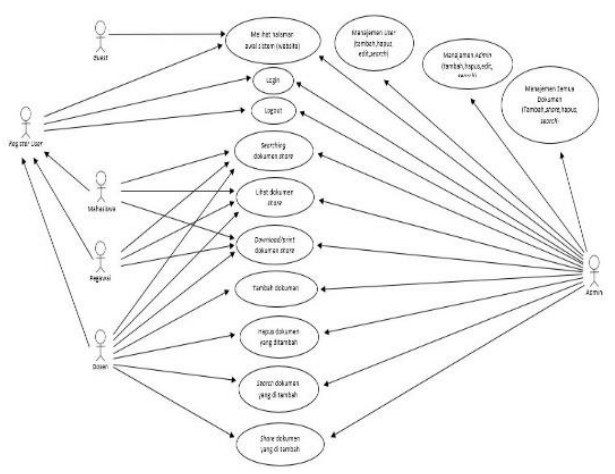

Gambar 4. Diagram Use Case Sistem

Diagram use case sistem menggambarlan keseluruhan fungsional sistem dengan menggunakan use case atau fungsi-fungsi yang tersedia dan aktor atau pengguna.

\section{Structural Model}

Permodelan struktural adalah dimana sistem yang dibangun dimodelkan dengan class diagram untuk memberikan gambaran setiap hubangan antar kelas-kelas yang terintegrasi dalam sistem. 
Tabel 2. Klasifikasi Objek

\begin{tabular}{|c|c|c|}
\hline Boundary & Control & Entity \\
\hline Interface & $\begin{array}{l}\text { Atribut : } \\
\text { Tambah, Share, } \\
\text { Edit, Hapus } \\
\text {,Lihat } \\
\text { Diklasifikasikan } \\
\text { ke dalam objek } \\
\text { : } \\
\text { Operasi Data } \\
\text { Admin } \\
\text { Atribut : } \\
\text { Lihat } \\
\text { Diklasifikasikan } \\
\text { ke dalam objek } \\
\text { : } \\
\text { Operasi Data } \\
\text { User }\end{array}$ & $\begin{array}{l}\text { Atribut : } \\
\text { Username, } \\
\text { Password } \\
\text { Diklasifikasikan } \\
\text { ke dalam objek } \\
\text { : } \\
\text { Admin } \\
\text { Atribut : } \\
\text { Username, } \\
\text { Password } \\
\text { Diklasifikasikan } \\
\text { ke dalam objek } \\
\text { : } \\
\text { User } \\
\text { Atribut : } \\
\text { Data Upload, } \\
\text { Data Share, Data } \\
\text { User, Data } \\
\text { Admin } \\
\text { Diklasifikasikan } \\
\text { ke dalam objek } \\
\text { : } \\
\text { Data Admin } \\
\text { Atribut : } \\
\text { Data Share } \\
\text { Diklasifikasikan } \\
\text { ke dalam objek } \\
\text { : } \\
\text { Data User }\end{array}$ \\
\hline
\end{tabular}

\section{Behavioral Models}

Behavioral Models Merupakan pemodelan sistem berdasarkan perilaku objek. Dalam permodelan perilaku objek menggunakan Sequence Diagram.

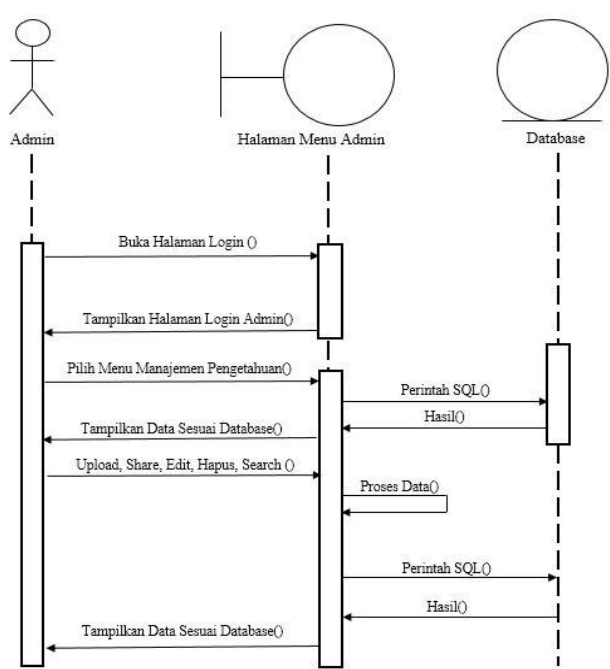

Gambar 5. Sequence Diagram Process Manajemen Pengetahuan Admin

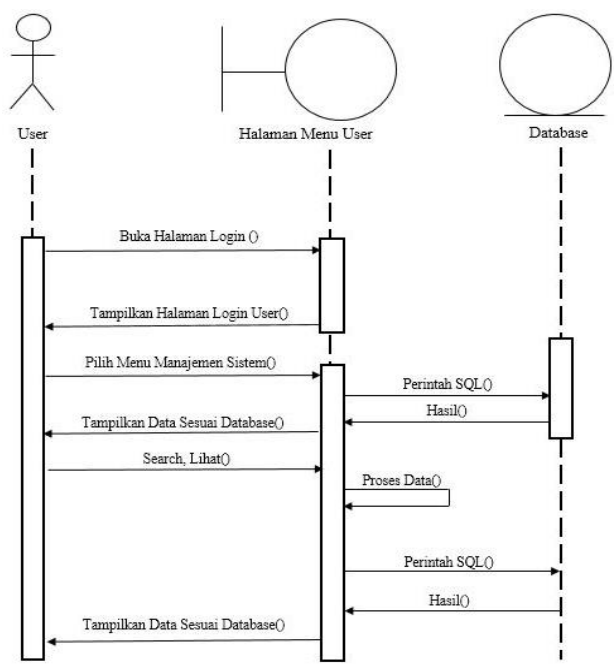

Gambar 6. Sequence Diagram Process Manajemen Pengetahuan User

4. Human Computer Interaction Layer Design.

Pada tahapan ini, digambarkan interaksi sistem dengan entitas lain dengan menggunakan dua gambaran yakni navigation design dan storyboard. Ada dua jenis jenis pengguna yaitu admin dan user. 


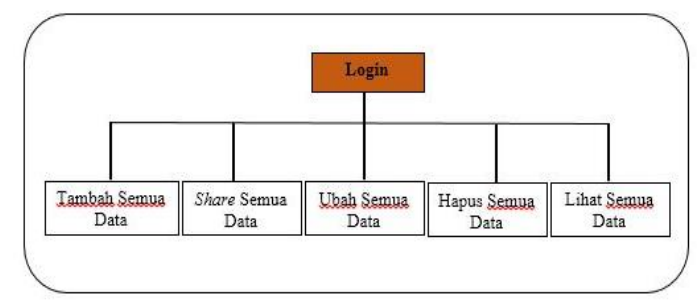

Gambar 7. Navigation Design Admin

admin sebagai pengelola sistem yang memiliki akses penuh atas sistem

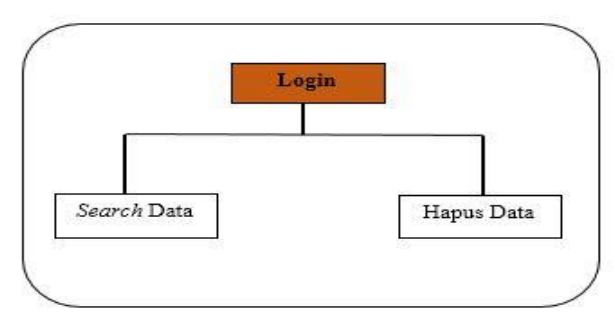

Gambar 8. Navigation Design User

admin sebagai pengelola sistem yang memiliki akses terbatas.

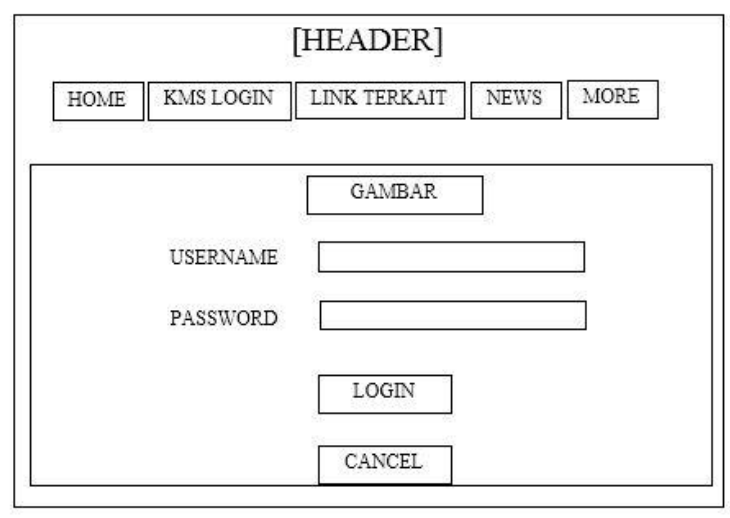

Gambar 9. Storyboard Login

Tahapan gambaran interaksi interface berikut adalah Storyboard. Storyboard digunakan untuk memvisualisasikan interface atau antarmuka halaman web yang akan dibangun sehingga memberikan gambaran tampilan dari aplikasi yang akan dihasilkan.

\section{HASIL DAN PEMBAHASAN}

\section{A. Implementasi Perancangan Sistem}

Implementasi perancangan sistem merupakan hasil perancangan dari halaman-halaman web yang sudah dibangun.

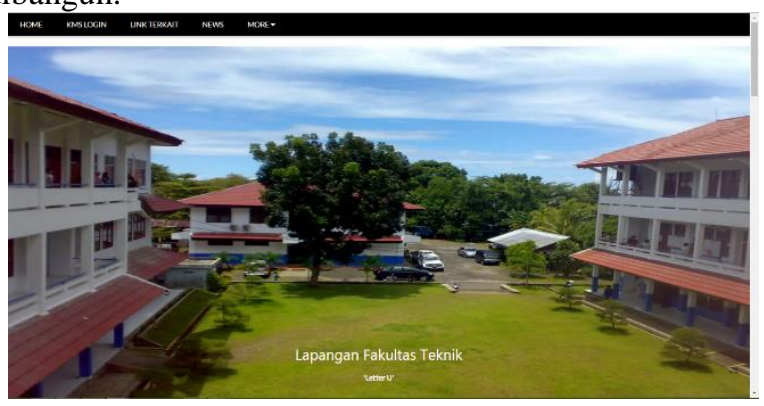

Gambar 9. Halaman Awal Sistem

Pada halaman awal sistem menampilkan gambargambar di Fakultas Teknik Universitas Sam Ratulangi



Gambar 10. Halaman Login Sistem

Pada halaman login menampilkan fitur sistem untuk melakukan proses login, pengguna dapat login dengan memilih form login sebagai user atau sebagai admin.

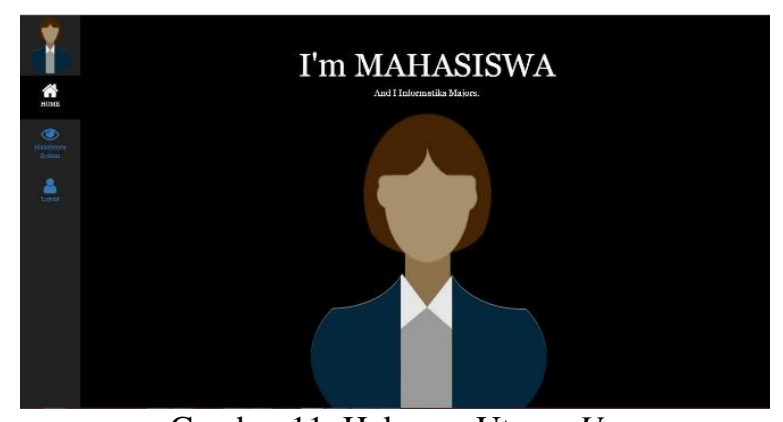

Gambar 11. Halaman Utama User

Halaman utama user terdiri dari gambar profile diri yang dimuat oleh user, nama dan jurusan user. 


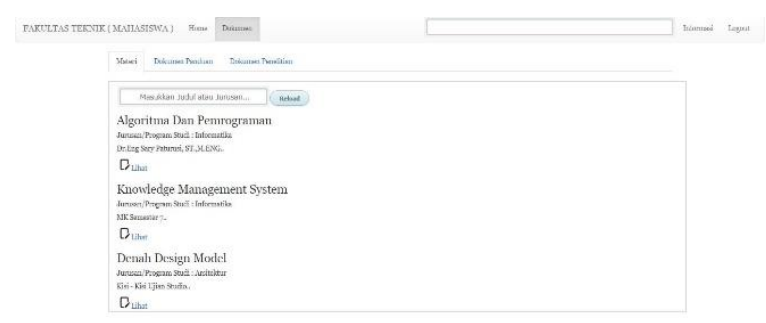

Gambar 12. Halaman Manajemen User

Halaman Manajemen User (untuk level pegawai dan mahasiswa) memuat dokumen-dokumen yang telah dibagikan oleh admin dan user (dosen) sesuai dengan kategori dokumen untuk dapat dilihat dan digunakan sesuai dengan kebutuhan.

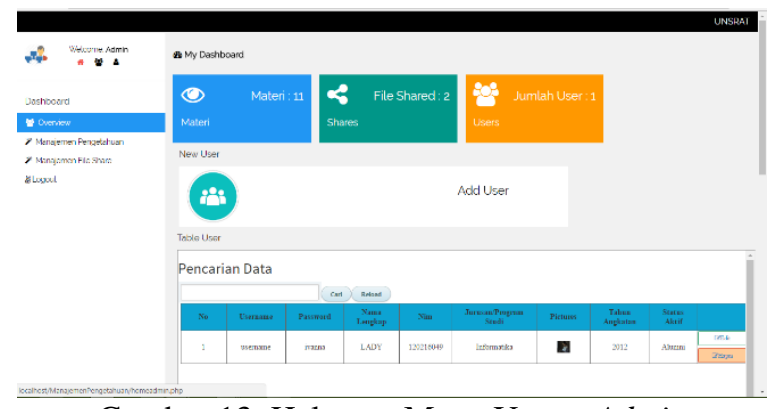

Gambar 13. Halaman Menu Utama Admin

Halaman menu utama admin merupakan halaman awal ketika proses login admin berhasil.



Gambar 14. Halaman Manajemen Pengetahuan

Halaman manajemen pengetahuan merupakan halaman dimana dokumen yang telah di upload dapat dikelola dan digunakan seperti menghapus, mengedit dan melihat dokumen.

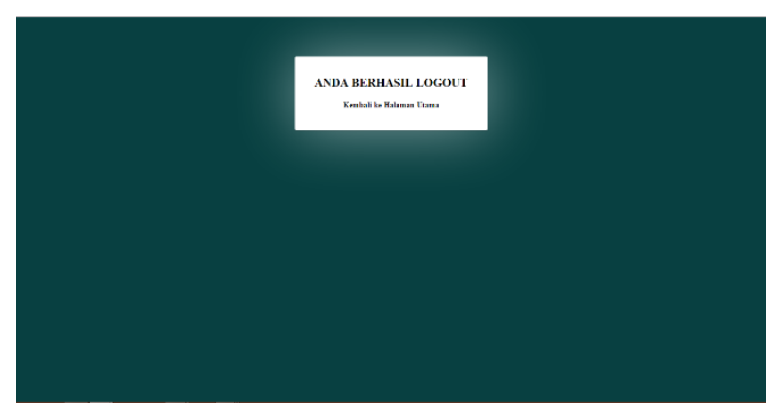

Gambar 15. Halaman Logout

\section{KESIMPULAN}

A. Kesimpulan

Kesimpulan penelitian adalah:

i. Sistem Manajemen Pengetahuan yang dibangun mampu menyimpan dan mengelola pengetahuan sehingga sistem dapat digunakan untuk Mendukung Proses Pembelajaran di Fakultas Teknik Universitas Sam Ratulangi.

ii. Rancang Bangun Sistem Manajemen Pengetahuan yang dihasilkan pada penelitian ini sesuai dengan kebutuhan dimana sistem dapat menambah, menyimpan, membagikan pengetahuan, sehingga pengetahuan yang dimiliki oleh fakultas dapat dimanfaatkan semaksimal mungkin Saran

Berikut terdapat beberapa saran untuk penelitian ini antara lain :

i. Sistem manajemen pengetahuan dapat dijadikan sarana alternatif untuk mengelola pengetahuan-pengetahuan yang ada di Fakultas Teknik UNSRAT agar dapat dimanfaatkan dengan lebih baik sesuai dengan kebutuhan fakultas.

ii. Seiring dengan berjalannya waktu, penelitian terhadap sistem manajemen pengetahuan ini dapat dilanjutkan dalam kajian yang lebih luas ke depanya sehingga sistem manajemen pengetahuan ini dapat menjadi lebih baik dan lebih bermanfaat bagi Fakultas Teknik Universitas Sam Ratulangi.

iii. Adanya unit yang dapat mengelola Sistem Manajemen Pengetahuan di Fakultas Teknik Universitas Sam Ratulangi secara profesional dan menyeluruh.

\section{DAFTAR PUSTAKA}

[1] Aisyah, E.S.N. dkk. 2015. "Prototipe Knowledge Management System Untuk Menunjang Pembelajaran Ilearning Dengan Model Seci". Debby E. Sondakh, S.Kom, MT. (ed), Proc. Konferensi Nasional Sistem Informasi 2015, Fakultas Ilmu Komputer - Universitas Klabat. Airmadidi, Indonesia. Pp. 110-115 No 15.

[2] Diartono, D.A. 2013. "Perancangan Grand Design Sistem Informasi Menuju Tata Kelola Universitas Yang Lebih Baik". A. Pribadi (ed), 
Proc. Konferensi Nasional Sistem Informasi 2013. STMIK Bumigoro Mataram. Mataram, Indonesia. Pp.122-125, No. 21.

[3] Johan. 2016. "Rancang Bangun Aplikasi Pendataan Potensi Desa/Kelurahan Berbasis Web". Skripsi S1 Teknik Elektro Universitas Sam Ratulangi. Manado.

[4] Kamsinah, "Metode Dalam Proses Pembelajaran Studi Tentang Ragam Dan Implementasinya". https://www.academia.edu/6806623 , 17 Juli 2016.

[5] Kristanti, T. dan Desinta, T. 2013. Knowledge Management System Desain Arsitektur Rumah Tinggal Pada Penta Rekayasa. A. Pribadi (ed), Proc. Konferensi Nasional Sistem Informasi 2013. STMIK Bumigoro Mataram. Mataram, Indonesia. Pp 673-678 No.204.

[6] Mardhotillah, S. 2011. Analisis dan Perancangan Knowledge Management System Berbasis WEB Dan WAP (Studi Kasus: SMAN 4 Tangerang Selatan). Skripsi Sarjana Komputer, Universitas Islam Negeri (UIN) Syarif Hidayatullah Jakarta.

[7] Pradana, A.T. dan Majapahit, S.A. 2015. Model Knowledge Management System Dalam Meningkatkan Kualitas Dari Proses Bisnis Di Organisasi. Debby E. Sondakh, S.Kom, MT. (ed), Proc. Konferensi Nasional Sistem Informasi 2015, Fakultas Ilmu Komputer Universitas Klabat. Airmadidi, Indonesia. Pp. 900-905 No 187.

[8] Rahmawati, 2014. Model Knowledge Management System Berbasis CBR Pada Service Center Elektronik, Drs. I Wayan Simpen, M.MSI. (ed), Proc. Konferensi Nasional Sistem Informasi 2014, Pusat Pengembangan, Penelitian, dan Pengabdian Masyarakat (LP4M). Makassar, Indonesia. Pp. 1724-1729 No. 327.

[9] Retnoningsih, E. Dan Utami, D.P. 2013. Penerapan Knowledge Management Pada Perguruan Tinggi (Studi Kasus Amik Bsi Purwokerto). Wahid Hasyim (ed). Prosiding SNST ke-4. Fakultas Teknik Universitas Wahid Hasyim. Semarang, Indonesia. Pp 152-158 No. 24.

[10] Saragih, H. Dkk. 2012. Sistem Informasi Knowledge Management Pada Perguruan Tinggi STMIK Widya Dharma Pontianak. Jurnal Teknik dan Ilmu Komputer, Vol.1, Pp.423-437, No.03.
[11] Sari, W.K dan Tania, K.D. 2014. Penerapan Knowledge Management System (KMS) Berbasis Web Studi Kasus Bagian Teknisi dan Jaringan Fakultas Ilmu Komputer Universitas Sriwijaya. Jurnal Sistem Informasi (JSI), VOL. 6, NO. 2, Pp. 2085-1588.

[12] Sentinuwo, S.R. 2010. Perancangan Model Knowledge Management System di Perguruan Tinggi dengan Pendekatan Balanced Scorecard. Jurnal TEKNO, Vol.08, Pp. 65-73, No.53.

[13] Sumadyo, M. dan Whidhiasih R.N. 2013. Rancang Bangun Document Management System Universitas " 45 ” Bekasi. Jurnal Penelitian Ilmu Komputer, System Embedded \& Logic, Vol.1, Pp.1-6, No.1.

[14] Surianti, Buono, A. dan Hermadi, I. 2014. Sistem Manajemen Pengetahuan Dalam Menanggulangi Penyakit Pada Tanaman Kelapa Sawit Menggunakan Pendekatan Usability Engineering, Drs. I Wayan Simpen, M.MSI. (ed), Proc. Konferensi Nasional Sistem Informasi 2014, Pusat Pengembangan, Penelitian, dan Pengabdian Masyarakat (LP4M). Makassar, Indonesia. Pp. 847-852 No 161.

[15] Susilawati, L. dan Alas S.M. 2011. Penerapan Knowledge Management Di Organisasi (Studi Kasis di Bagian Pemasaran). Yudi Agusta (ed). Proc. Konferensi Nasional Sistem Informasi 2011, STMIK Potensi Utama. Medan, Indonesia. Pp. $557-565$.

[16] Tan, R. 2010. Perancangan Model Manajemen Pengetahuan Menggunakan Model Nonaka Takeuchi (Studi Kasus Administrasi Akademik). Jurnal Informatika, Vol.6, Pp.51-64, No.1.

[17] Thoyyibah, T., Buono, A. dan Hermadi, I. 2014. Pengembangan Sistem Berbasis Pengetahuan Untuk Pemilihan Bibit Kelapa Sawit Menggunakan Pendekatan Usability Engineering, Drs. I Wayan Simpen, M.MSI. (ed), Proc. Konferensi Nasional Sistem Informasi 2014, Pusat Pengembangan, Penelitian, dan Pengabdian Masyarakat (LP4M). Makassar, Indonesia. Pp. 842- 847 No 160.

[18] Wijaya, K.H. 2015. Sistem Pendukung Keputusan Penerima Beasiswa Dengan Metode Techinique For Order Preference By Similarity To Ideal Solution Di Universitas Sam Ratulangi ,/;/ 




Yuliani Yesinia Ivanna

Kaawoan, lahir di Manado, Provinsi Sulawesi Utara. Anak ke-2 dari 3 bersaudara dengan pendidikan Sekolah Dasar Garuda MManado. Penulis lalu melanjutkan ke Sekolah Menengah Pertama Negeri 6 Manado. Lalu ke pendidiksn tingkat atas SMA Negeri 7 Manado dengan mengambil Ilmu

Pengetahuan Alam. Pada tahun 2012 melanjutkan ke Perguruan Tinggi di Universitas Sam Ratulangi dengan mengambil Jurusan Teknik Informatika. Pada Tahun 2015 bulan Agustus sampai Bulan Oktober melakukan Kerja Praktek di Badan Pertanahan Kota Manado dengan Judul Projek Membuat Aplikasi Input Lembar Surat Disposisi Badan Pertanahan Kota Manado. Dan Pada Tahun 2016, penulis membuat Skripsi demi memenuhi Syarat Sarjana (S1) dengan penelitian berjudul Rancang Bangun Sistem Manajemen Pengetahuan Untuk Mendukung Proses Pembelajaran di Fakultas Teknik Universitas Sam Ratulangi, yang dibimbing oleh dua dosen pembimbing yaitu Dr.Eng Steven Sentinuwo, S.T,.M.TI dan Alwin M. Sambul, ST., M.Eng., Ph.D sehingga pada tanggal 29 Oktober 2017 penulis resmi lulus di Teknik Informatika Universitas Sam Ratulangi Manado menyandang gelar Sarjana Komputer dengan Predikat Sangat Memuaskan. 